\title{
ALLEMEYER, Marie Luisa, » Kein Land ohne Deich...! «. Lebenswelten einer Küstengesellschaft in der Frühen Neuzeit
}

\section{Christophe Duhamelle}

\section{OpenEdition}

\section{Journals}

Édition électronique

URL : http://journals.openedition.org/ifha/586

DOI : $10.4000 /$ ifha. 586

ISSN : 2198-8943

\section{Éditeur}

IFRA - Institut franco-allemand (sciences historiques et sociales)

Référence électronique

Christophe Duhamelle, «ALLEMEYER, Marie Luisa, » Kein Land ohne Deich...! «. Lebenswelten einer Küstengesellschaft in der Frühen Neuzeit », Revue de I'IFHA [En ligne], Date de recension, mis en ligne le 01 janvier 2007, consulté le 22 septembre 2020. URL : http://journals.openedition.org/ifha/586 ; DOI https://doi.org/10.4000/ifha.586

Ce document a été généré automatiquement le 22 septembre 2020.

(CIFHA 


\title{
ALLEMEYER, Marie Luisa, » Kein Land ohne Deich...! «. Lebenswelten einer Küstengesellschaft in der Frühen Neuzeit
}

\author{
Christophe Duhamelle
}

1 Il existe en Allemagne une mythologie du combat mené contre la mer par le peuple des digues, rude et solidaire - elle doit beaucoup au roman de Theodor Storm, Der Schimmelreiter (traduit en français sous le titre L'homme au cheval blanc) et au film national-socialiste tiré de cette œuvre. M.L.A. se propose au contraire, en se fondant sur les abondantes archives engendrées par les conflits à propos des digues en Schleswig-Holstein aux XVIIe et XVIIIe s., de faire de cette " solidarité » l'objet d'une étude critique et de l'inscrire dans le contexte changeant d'une société et de ses représentations.

2 Apparemment, l'évolution suit un schéma linéaire. Au départ, les digues sont initiées, réalisées et entretenues par les paroisses, regroupées en Landschaften disposant d'une grande autonomie, et en ligues de digue (Deichband) gouvernant chaque ensemble gagné sur la mer, le Koog (Köge au pluriel). Les plus gros propriétaires (les Interessenten) sont responsables chacun d'une partie de la digue (le Deichkabel) ; s'ils manquent à leurs devoirs, ils sont menacés de la Verspatung, une expropriation symboliquement exprimée par une pelle plantée dans le Deichkabel. À l'arrivée, le prince (la région constitue une portion autonome, car située dans l'Empire, du royaume de Danemark) cherche à contrôler de plus en plus les digues, à s'en réserver le profit et à promouvoir une professionnalisation de leur entretien : il instaure en 1609 la fonction de Deichsgraf (comte de la digue), forge à partir de 1612 la notion d'Anwachsregal lui réservant toute terre gagnée sur la mer et lui permettant d'attribuer seul le droit d'endiguer (octroyierte Köge) non plus aux paroisses littorales mais à des spécialistes souvent néerlandais, il institue enfin en 1616 le système de la Kommuniondeichung selon lequel l'entretien de la digue est confié à des salariés. Le règlement de 1803, 
créant par autorité royale trois Deichbände généraux et généralisant la Kommuniondeichung, scelle cette évolution.

3 Le détail des conflits, mais aussi des négociations et des arrangements, vient cependant fortement nuancer ce schéma. Les nouvelles institutions font l'objet parfois d'un rejet, parfois d'une appropriation par les Landschaften (c'est le cas des comtes de digue), le plus souvent d'une adaptation réciproque où chacun trouve son compte et où les paysans des Köge savent conserver leur pouvoir local. Surtout, l'essentiel des conflits se situe ailleurs et permet à M.L.A. de déplacer la perspective : ce qui est en jeu est moins un duel entre prince et Landschaften qu'une redéfinition constante de ce qu'est la responsabilité envers la digue et les dangers qui la menacent. Un Koog ancien et désormais entouré de terres fermes est-il tenu de contribuer à l'entretien de la digue qui s'est déplacée plus loin ? Comment empêcher les habitants d'utiliser la digue pour le charroi ou le bétail, au risque de la fragiliser ? À partir de quel moment une rupture de digue est-elle le résultat d'une négligence ou celui d'un déchaînement exceptionnel des flots ? Faisant rejouer les tensions sociales, les représentations religieuses et les conceptions du bien commun, ces conflits suscitent envers les différentes institutions concernées des sollicitations variables.

4 La même subtilité prévaut dans l'analyse que mène M.L.A. des manières de considérer la sécurité procurée par la digue et les catastrophes qui régulièrement la submergent. Là encore, un schéma simple pourrait être invoqué : au début, toute catastrophe est interprétée comme une punition divine ; à la fin, une conception sécularisée des choses prévaut. Mais tout au long de la période la réflexion porte justement sur la limite entre le naturel et le surnaturel, non sur l'opposition entre les deux. Au XVIe s. déjà le droit attribue la responsabilité de la rupture d'une digue mal entretenue à ceux qui l'ont négligée et au XVIIIe s. encore la volonté divine est placée aux confins de la technique, rétablissant l'équilibre naturel lorsque l'homme va trop loin dans ses projets (c'est l'argument de l'Hydrotheologie de Fabricius en 1734).

5 Au moment où l'historiographie allemande, après un timide engouement pour l'espace, s'attache plus durablement à une étude historique des relations entre l'homme et son environnement, au moment aussi où elle accorde une grande importance aux études de cas permettant de nuancer une vision trop dichotomique du pouvoir, cet ouvrage ouvre donc plusieurs horizons interprétatifs à la présentation nuancée et vivante d'une société singulière. Bien que l'auteur s'attache parfois un peu trop au détail des conflits, qui auraient gagné à être mieux insérés dans la pratique concrète des réunions communales, des règlements successoraux et des intérêts économiques, son ouvrage constitue à coup sûr une contribution originale à l'histoire sociale et à la géographie historique de l'Allemagne moderne.

Christophe DUHAMELLE (Université d'Amiens) 